\title{
Investigation of the contribution of concentrated growth factor (CGF) and processed lipoaspirate (PLA) to wound healing in diabetic rats
}

\author{
(D)Ali Bolat, Yıldırım Gültekin \\ Kırıkkale University, School of Medicine, Department of Cardiovascular Surgery, Kırıkkale, Turkey
}

Cite this article as: Bolat A, Gültekin Y. Investigation of the contribution of concentrated growth factor (CGF) and processed lipoaspirate (PLA) to wound healing in diabetic rats. J Health Sci Med 2021; 4(1): 33-37.

\begin{abstract}
Aim: The aim of the study is to show the effectiveness of concentrated growth factor (CGF) and processed lipoaspirate (PLA) in wound healing in diabetic rats.

Materyal and Method: A total of 30 rats were used in the study. It was divided into 3 groups as concentrated growth factor, processed lipoaspirate and control group. The rats were made diabetic using Sreptozotocin IP. A $5 \mathrm{~mm}$ diameter wound was created on one of the hind legs of all rats by using a punch. Concentrated growth factor and processed lipoaspirate were applied to the lesions. Daily wound size and wound condition were recorded on days 3,5 and 10. At the end of the study, blood samples were taken for TNF- $\alpha$, TGF- $\beta$, IL-1, PDGF, FGF and VEGF measurements before the rats were sacrificed.

Results: The mean wound diameters measured on the $3^{\text {rd }}$ day in the study were $4.6 \pm 0.06 \mathrm{~mm}$ in the control group, $4.1 \pm 0.05$ $\mathrm{mm}$ in the concentrated growth factor group, and $4.4 \pm 0.07 \mathrm{~mm}$ in the processed lipoaspirate group. The wound diameters measured on the $5^{\text {th }}$ day were $3.1 \pm 0.04 \mathrm{~mm}$ in the control group, $1.6 \pm 0.05 \mathrm{~mm}$ in the concentrated growth factor group and $2.7 \pm 0.06 \mathrm{~mm}$ in the processed lipoaspirate group $(\mathrm{p}<0.01)$. The mean closure time of wounds was $5.3 \pm 1.1$ days in the concentrated growth factor group, $7.1 \pm 1.4$ days in the processed lipoaspirate group, and $9.4 \pm 0.5$ days in the control group. All of the wounds were healed in all groups on the $10^{\text {th }}$ day. This improvement rate in the concentrated growth factor group was statistically significant compared to the other two groups $(\mathrm{p}<0.01)$. Concentrated growth factor and PLA increased the speed of wound healing in diabetic rats. Inflammatory marker levels (TNF- $\alpha$, TGF- $\beta$, IL-1, PDGF, FGF, VEGF) obtained from blood samples were higher than normal in all rats and there was no significant difference between the groups $(p>0.05)$.

Conclusion: In this study, it was shown that concentrated growth factor application was more effective than processed lipoaspirate application in wound healing in diabetic rats.
\end{abstract}

Keywords: CGF, PLA, diabetic rat, ulcer

\section{INTRODUCTION}

Wound is the disruption of the tissue integrity of the skin or mucosa for many different reasons such as abrasions, cuts, stings, bruises, burns, venous ulcers, surgical incisions and diabetic ulcers. Damaged tissue repair begins with hemostasis. Then the inflammatory period begins and is completed in 24-48 hours. It is completed in 3 stages as proliferative and maturation stages $(1,2)$.

When the vessel wall is damaged, thrombocytes contact the collagen in the opened vessel wall and form a temporary clot and hemostasis is achieved. Inflammatory cells migrate towards the wound area and begin to remove apoptotic cells and bacteria from the wound area. Cytokines are released immediately after tissue damage in the inflammatory period. Cytokines guide the healing process (3).
Proliferation Phase is a process that starts on the $2^{\text {nd }}$ day after the injury and continues for 3 weeks. At this stage, a basically permeable barrier is created. Epithelialization and contraction develop (4).

In response to cytokines and growth factors released from inflammatory cells in the wound area, fibroblasts begin to synthesize new extracellular matrix and immature Type III collagen. Epithelial cells originating from the basal layer at the edges of the wound create a new surface on the wound.

The remodelization phase starts in the $3^{\text {rd }}$ week after the proliferation phase. At this stage, the number of fibroblasts in the wound area decreases. Collagen production reaches equilibrium and epithelization is completed. (5). 
Especially thrombocytes stimulate angiogenesis by secreting transforming growth factor beta (TGF- $\beta$ ), platelet derivated growth factor (PDGF), interlokin 1 (IL1), platelet aktivated growth factor (PAF), transforming growth factor alfa (TGFa), tumor nekroz factor (TNFa), fibroblast growth factor (FGF), epidermal growth faktor (EGF) (6).

In order to increase these effects, the use of plateletenriched plasma-rich platelet (PRP) and plasma-rich fibrin (PRF) or the collection and injection of these directly activated factors are techniques used to accelerate wound healing (7).

Growth factors in platelet cells provide healing. Platelet cells injected rupture when they encounter calcium in the body. The Growth Factors in it repair the damaged tissues in the injected area. However, not all Platelet cells have a chance to encounter Calcium. In fact, this is the feature that distinguishes CGF from PRP. CGF is obtained by separating minimum $97 \%$ of the growth factors from the Platelet and bringing it to high density (8).

Concentrated growth factor has the isolation of a fibrin matrix denser in terms of growth factors compared to PRP and PRF (9). Therefore, CGF can be expected to have regenerative potential and better properties for clinical manipulation (10). CGF and PRF contain almost the same components; however, the high tensile strength and viscosity of CGF protect growth factors better than proteolysis (11).

Another method for wound healing is MSC injection. In theory, cells that are not limited in their ability to reproduce and renew themselves and transform into any cell are defined as stem cells (12).

While embryonic stem cells can be obtained from early blastocysts, adult stem cells can also be obtained from non-embryonic tissues. These are cord blood, hematopoietic stem cells, fat and skin cells (13).

There are local and systemic factors affecting wound healing. Factors such as blood flow in the area of the wound, cytokines and growth factors, genetic and immunological disorders, diabetes, infection, radiotherapy, chemotherapy, inappropriate nutrition, steroid drug use affect wound healing (14)

Microvascular disorder, which is one of the important complications of diabetes, neuropathy causing loss of sensation in the skin, and weakening of the ability to fight infection are the main factors that delay wound healing (15).

An excisional wound model is used in DM-induced rats to observe wound healing. An open wound is created and the time-dependent closure rate of the wound is recorded. Granulation formation, collagen deposition, reepithelization and constriction can be investigated with this model (16).

Our aim in this study is to compare the effectiveness of CGF and PLA on wound healing in the excisional wound model created in diabetic rats.

\section{MATERIAL AND METHOD}

A total of 30 male Wistar albino rats weighing between 300-350 g were used in this study. Experimental animals were obtained from Kirıkkale University Hüseyin Aytemiz Experimental Research and Application Laboratory. The experiment was carried out in accordance with the principles of "Guide for the Care and Use of Laboratory Animals". Approval was obtained from Kirıkkale University Animal Experiments Local Ethics Committee for the study. (Date: 02.05.2016/Issue: 16/54).

Diabetic Rat: Rats were carried out diabetic using Sreptozotocin (STZ, Sigma Mo, USA) $55 \mathrm{mg} / \mathrm{kg}$ intraperitoneally (9). It was confirmed that morning fasting sugars were higher than $250 \mathrm{mg} / \mathrm{dL}$ with blood taken from the tail 1 week after the injection. Three groups were formed with 30 rats at 12 weeks of age. Groups consisted of 10 male rattan. One of the groups was given CGF (CGF group), the other was PLA (PLA group). Group 3 was the control group (Control group).

Wound: A full-thickness skin wound was created on the legs of all rats under anesthesia with xylazine $\mathrm{HCl}$ (1 $\mathrm{mg} / \mathrm{kg}$ i.m.) + ketamine HCI (50 mg/kg i.m.) using a 5 $\mathrm{mm}$ punch under sterile conditions. The diameters were recorded by examining the wound areas on the $0,3,5$ and 10 days after treatment.

Treatment Method: 1 day later, mesenchymal stem cells (MSC) were applied to PLA group, CGF was applied to CGF group and no medication was given to control group.

CGF preparation: Commercial kit $\left(\right.$ Truecell $^{\circledR}$ ) was used. The kit consists of two tubes with citrate as anticoagulant substance in A-tube and calcium chloride in tube B for platelet activation. $4 \mathrm{ml}$ of blood taken from a rat was put into A-tube and centrifuged at $2500 \mathrm{rpm} / \mathrm{min}$ for 10 minutes. BuffyCoat layer containing dense thrombocytes and leukocytes on the surface and serum plasma part were transferred from A-tube to B-tube. It was centrifuged for 5 minutes at $4000 \mathrm{rpm} / \mathrm{min}$. $2 \mathrm{ml} \mathrm{CGF}$ was collected, which was released from activated platelets, passed into plasma and accumulated on the surface. Then, $0.2 \mathrm{ml}$ was injected into the wound area of each rat.

PLA Preparation: Stem cells obtained from rat adipose tissue were prepared as $5 \times 10^{6}$ cells $/ \mathrm{ml}$. It was supplied under cold chain conditions. (Live laboratories Hospital, Istanbul, Turkey). Lipoaspirate was washed with buffer 
solutions (PBS: phosphate buffer solution was used for this purpose). Enzymatic destruction was performed with collagenase. The cell layer was obtained by separating the supernatant layer by centrifugation. It was carried out by cell culture and passaging after this step to obtain PLA alone.

Sacrification: On the $12^{\text {th }}$ day, subjects were sacrificed and blood samples were taken.

ELISA: TNF- $\alpha$, TGF- $\beta$, IL-1, PDGF, FGF and VEGF levels were measured from the blood samples taken by ELISA method.

During the experiments, five rats per cage were followed up. Maintained under standard environmental conditions (12-hour light/dark cycle, temperature $\sim 21^{\circ} \mathrm{C}$ ). It was fed ad libitum with standard rat chow and water.

\section{Statistical Analysis}

SPSS version 20.0 (SPSS; Chicago, IL, USA) software was used for statistical analysis. Normally distributed data were given as means \pm standard deviation and nonnormally distributed data as mean $\pm 25 \%$. Chi-square and Fisher's exact tests were used to compare categorical variables. Mann-Whitney U-test (MWU) and KruskalWallis test (Bonferroni-adjusted) were used to compare continuous data with non-normal distributions. A p value of $<0.05$ was considered statistically significant.

\section{RESULTS}

The study was conducted on 30 diabetic rats. The rats were divided into 3 groups and there were 10 rats in each group $(\mathrm{n}=10)$. A full thickness wound was created with a $5 \mathrm{~mm}$ punch. PLA was given to the wound in group 1. CGF was given to the wound in group 2. Group 3 was the control group. Wound diameters were measured and recorded on the $3^{\text {rd }}$ day, $5^{\text {th }}$ day and $10^{\text {th }}$ day. Blood samples were taken on the $12^{\text {th }}$ day and the rats were sacrificed. TNF- $\alpha$, TGF- $\beta$, IL-1, PDGF, FGF and VEGF levels were measured to show the severity of the inflammatory process. Blood levels of inflammatory markers were higher than normal. However, there was no significant difference between the groups ( $\mathrm{p}>0.05)$. The data are shown in Table 1.

\begin{tabular}{|lcccc|}
\hline \multicolumn{5}{|l|}{ Table 1. Inflammatory markers } \\
\hline $\mathbf{n}=\mathbf{1 0}$ & CGF group & PLA group & Control group & P \\
\hline TNF- $\alpha(\mathrm{pg} / \mathrm{ml})$ & $13.4 \pm 1.4$ & $14.3 \pm 2.6$ & $13.1 \pm 1.5$ & 0.369 \\
TGF- $\beta(\mathrm{ng} / \mathrm{ml})$ & $20.1 \pm 2.9$ & $18.7 \pm 3.7$ & $20.8 \pm 3.8$ & 0.481 \\
IL-1 $(\mathrm{pg} / \mathrm{ml})$ & $0.8 \pm 0.2$ & $1.0 \pm 0.3$ & $0.90 \pm 0.2$ & 0.122 \\
PDGF $(\mathrm{pg} / \mathrm{mL})$ & $39.8 \pm 4.7$ & $37.9 \pm 6.7$ & $42.47 \pm 4.9$ & 0.21 \\
FGF $(\mathrm{ng} / \mathrm{mL})$ & $17.8 \pm 4.7$ & $17.6 \pm 3.4$ & $15.5 \pm 3.6$ & 0.202 \\
VEGF $(\mathrm{pg} / \mathrm{ml})$ & $201.1 \pm 4.7$ & $198.9 \pm 8.6$ & $197.7 \pm 6.3$ & 0.525 \\
\hline $\begin{array}{l}\text { Abbreviations: CGF: Concentrated growth factor, PLA: Processed lipoaspirate, PDGF: } \\
\text { Platelet-derived growth factor, TGF- } \beta \text { : Transforming growth factor, TNF- } \alpha \text { : Tumor } \\
\text { necrosis factor, VEGF: Vascular endothelial growth factor, FGF: Fibroblast growht } \\
\text { factor, IL-1: Interlökin 1 }\end{array}$ & & & \\
\hline
\end{tabular}

The mean wound diameters measured on the $3^{\text {rd }}$ day were $4.6 \pm 0.06 \mathrm{~mm}$ in the control group, $4.1 \pm 0.05 \mathrm{~mm}$ in the CGF group, and $4.4 \pm 0.07 \mathrm{~mm}$ in the PLA group. Wound diameters measured on the $5^{\text {th }}$ day were $3.1 \pm 0.04 \mathrm{~mm}$ in the control group, $1.6 \pm 0.05 \mathrm{~mm}$ in the CGF group, and $2.7 \pm 0.06 \mathrm{~mm}$ in the PLA group. There was a significant difference in wound diameters measured on both days between CGF and PLA and control group $(p<0.01)$. In addition, a significant difference was found between CGF and PLA groups $(\mathrm{p}<0.01)$. The fastest improvement was in the PLA group. The data are shown in Table 2 and Figure 1.

\begin{tabular}{|c|c|c|c|}
\hline$n=10$ & $3^{\text {rd }}$ day $(\mathrm{mm})$ & $5^{\text {th }}$ day $(\mathrm{mm})$ & $\mathbf{P}$ \\
\hline CGF group & $4.1 \pm 0.06$ & $1.6 \pm 0.004$ & $<0.001$ \\
\hline PLA group & $4.4 \pm 0.05$ & $2.7 \pm 0.05$ & $<0.001$ \\
\hline Control group & $4.6 \pm 0.07$ & $3.1 \pm 0.06$ & $<0.001$ \\
\hline
\end{tabular}

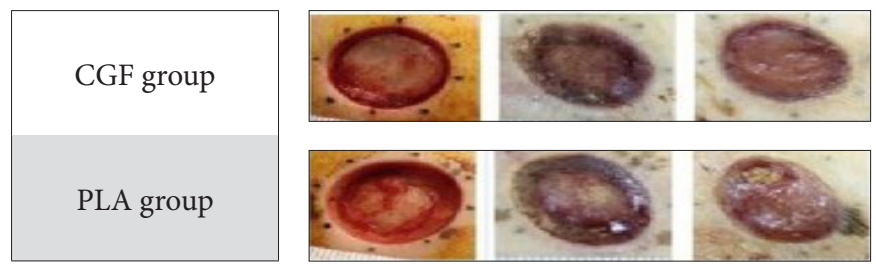

Figure 1. Wound healing status on the first, $5^{\text {th }}$ and $7^{\text {th }}$ days

The mean closure time of wounds was $5.3 \pm 0.32$ days in the CGF group, $7.1 \pm 0.51$ days in the PLA group, and 9.4 \pm 0.4 days in the control group. A significant difference was found between the mean healing time of wounds, CGF and PLA and the control group $(\mathrm{p}<0.01)$. There was also a significant difference between CGF and PLA groups $(p<0.01)$. It was observed that the fastest closure was in the CGF group and the slowest closure was in the control group. In the 10-day follow-up period, the wounds on the legs of all rats made diabetic healed. The data are shown in Table 3 and Figure 2.

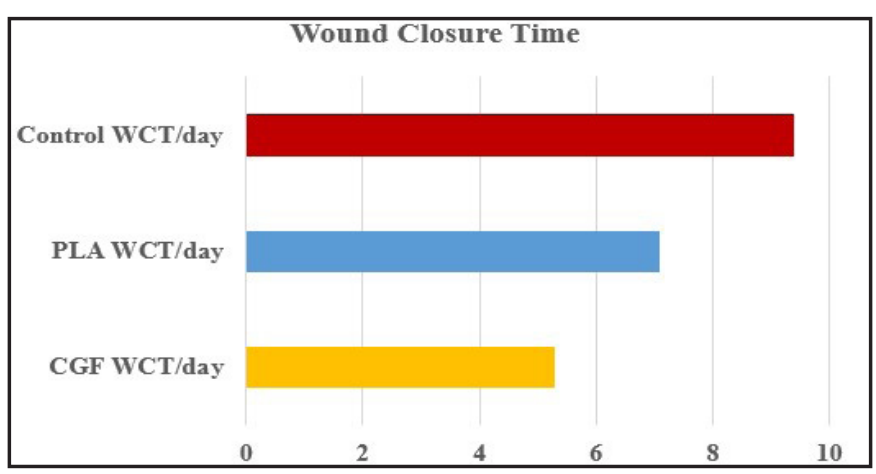

Figure 2. Wound closure time (WCT)

\section{Table 3. Wound closure time}

\begin{tabular}{|lcccc|}
\hline $\mathbf{n}=\mathbf{1 0}$ & CGF group & PLA group & Control group & $\mathbf{p}$ \\
\hline WCT (mean \pm std) & $5.3 \pm 0.32$ & $7.10 \pm 0.51$ & $9.4 \pm 0.4$ & $<0.01$ \\
\hline $\begin{array}{l}\text { Abbreviations: WCT: Wound closure time, CGF: Concentrated growth factor, } \\
\text { PLA: }\end{array}$ &
\end{tabular}




\section{DISCUSSION}

Wounds can be acute (surgery, burns, penetrating injuries) or chronic (pressure sores, venous stasis ulcers, diabetic wounds, ischemic wounds, etc.).Chronic wounds are an important health problem affecting a significant portion of the population in developed countries and impairing the quality of life. In addition, its treatment brings a serious financial burden (17).Wound healing is the process of restoring the anatomical and functional properties of the tissue by regularly completing certain wound healing phases. It is known that various factors affect the wound healing process negatively. These; malnutrition, infections, diabetes, hypoxia, circulatory disorder, immunosuppression, aging and chronic diseases (18).

In vivo wound models are incisional, excisional, burn and frozen models.Models applied for cases where wound healing is impaired are malnutrition, ischemia, infection, compression and diabetes models. In this experiment, we investigated wound healing in diabetic rats using an excisional wound model (19).

It has been shown that a significant part of the proliferation, migration and vascular formation promoting effects of PRP are achieved through exosome-like molecules released from platelets into the plasma (20). The effect of PRP on wound healing has been mainly associated with growth factors released from platelets (21). CGF is more intense in terms of growth factors compared to PRP and PRF (22). In our study, instead of PRP, growht factors (GF) released from leukocyte-free and activated PRPs were applied to the wound area.

The most important inflammation cytokines in wound healing are TNF- $\alpha$, TGF- $\beta$, IL-1, PDGF, FGF and VEGF. (23). Blood levels in the groups were measured by ELISA method. All were found higher than normal levels. But there was no statistically significant difference between them ( $p>0.05)$. The similar inflammatory mediator levels were interpreted as similar rates of local and systemic inflammation in the treatment groups. The high levels were interpreted as tissue repair and healing continued. It has been shown that the proliferation phase, which is the last phase of wound healing, can continue for up to 6 weeks (24). Towards the end of this process, it was thought that there might be a differentiation between the treatment group and the treatment group.

In wound healing, epithelial cells migrate from the beginning of the injury until the entire damaged surface is covered. Wound contraction begins to occur 7 days after injury, and myofibroblasts play an important role at this stage. Many factors affect the healing and contraction process at a rate of approximately $0.75 \mathrm{~mm} /$ day (5-7). In this study, the mean wound diameters on the $3^{\text {rd }}$ day were $4.6 \pm 0.06 \mathrm{~mm}$ in the control group, $4.1 \pm 0.05 \mathrm{~mm}$ in the CGF group, and $4.4 \pm 0.07 \mathrm{~mm}$ in the PLA group. Wound diameters measured on Day 5 were $3.1 \pm 0.04 \mathrm{~mm}$ in the control group, $1.6 \pm 0.05 \mathrm{~mm}$ in the CGF group, and $2.7 \pm 0.06 \mathrm{~mm}$ in the PLA group ( $\mathrm{p}<0.01)$. These results show that both PLA and CGF increase wound repair in diabetic rats compared to the control group. The fastest recovery seems to be in the CGF group.

In an animal study where the reconstruction of bone defects was evaluated using CGF, PRP and PRF, they were compared in terms of their osteogenic potential, but no statistically significant difference was found between them (25). First developed by Sacco (26) in 2006, CGF, one of the second-generation platelet concentrations, demonstrated the potential to accelerate osteogenesis when used in sinus augmentation.

In the rat calvarial bone defect regeneration study of Khojasteh et al. (27) it was reported that MSC application yielded more successful results than PRP.

It has been shown in different studies that stem cell application will contribute to the treatment of difficultto-heal wounds such as diabetic ulcers (28).

Walter et al. (20) MSCs associated their contribution to wound healing with the chemotactic mediators they secrete, such as TGF-1 $\beta$, IL-6, and IL-8. The clinical benefits of MSCs can be summarized as stimulation of cellular repair, attenuation of inflammation, enhancement of angiogenesis and therapeutic cell migration (29).

The mean closure time of the wounds in the study was $5.3 \pm 0.32$ days in the CGF group, $7.1 \pm 0.51$ days in the PLA group, and $9.4 \pm 0.4$ days in the control group. A significant difference was found between the mean healing time of wounds, CGF and PLA and the control group $(\mathrm{p}<0.01)$. There was also a significant difference between CGF and PLA groups $(\mathrm{p}<0.01)$. It was observed that the fastest closure was in the CGF group and the slowest closure was in the control group. In the 10-day follow-up period, the wounds on the legs of all rats made diabetic healed. These results in diabetic rats have shown that CGF and PLA are effective in wound healing as in other studies. In the study, it was found that CGF is more effective than PLA. We think that the reason for CGF's effectiveness is its active and long effect.

\section{CONCLUSION}

In this study, CGF and PLA applications are two important methods that increase wound healing, but CGF application has been shown to be a more effective method than PLA in wound healing. 


\section{ETHICAL DECLARATIONS}

Ethics Committee Approval: Approval was obtained from Kurıkkale University Animal Experiments Local Ethics Committee for the study. (Date: 02.05.2016/Issue: 16/54).

Referee Evaluation Process: External double-blind referee assessment.

Financial Disclosure: This study was supported by the Kırkkale University scientific research project.

Conflict of Interest Statement: The authors have no conflicts of interest to declare.

Author Contributions: All of the authors declare that they have all participated in the design, execution, and analysis of the paper, and that they have approved the final version.

\section{REFERENCES}

1. Harper D, Young A, McNaught CE. The physiology of wound healing. Surgery (Oxford) 2014; 32: 445-50.

2. Macdonald J, Asiedu K. WAWLC: World Alliance for Wound and Lymphedema Care. Wounds 2010; 22: 55-9.

3. Sayek İ, Ozmen MM, Temel Cerrahi El Kitabı, Güneş Tıp Kitabevleri, Ankara, 2009.

4. Coşkun Ö, Uzun G, Dal D, ve ark. Kronik yarada tedavi yaklaşımları. Gülhane Tıp Derg 2016; 58: 207-28.

5. Rajpaul K. Biofilm in wound care. Br J Community Nurs; Suppl Wound Care: 2015; 6: 10-1.

6. Broughton G, Janis JE, Attinger CE. The basic science of wound healing. Plast Reconstr Surg 2006; 117: 125-34.

7. Jeffcoate J.W, Price P, Harding G.K.Wound healing and treatments for people with diabetic foot ulsers. Diabetes/Metabolism Research and Reviews 2004; 20: 78-89.

8. Martino MM, Tortelli F, Mochizuki M, al. Engineering the growth factor microenvironment with fibronectin domains to promote wound and bone tissue healing. Sci Transl Med 2011; 3: 100-89.

9. Rodella LF, Favero G, Boninsegna R, et al. Growth factors, CD34 positive cells, and fibrin network analysis in concentrated growth factors fraction. Microsc Res Tech 2011; 74: 772-7.

10. Chen Y, Cai Z, Zheng D, et al. Inlay osteotome sinus floor elevation with concentrated growth factor application and simultaneous short implant placement in severely atrophic maxilla. Scientific reports 2016; 6: 273-8.

11. Kim T-H, Kim S-H, Sándor GK, Kim Y-D. Comparison of plateletrich plasma (PRP), platelet-rich fibrin (PRF), and concentrated growth factor (CGF) in rabbit-skull defect healing. Archives of oral biology 2014; 59: 550-8.

12. İnan S, Ozbilgin K. Kok Hucre Biyolojisi. Sağlıkta Birikim. Cilt 1, Say1 5, 2009: 11-23.

13. Kok IJ, Peter SJ, Archambault M, et al. Investigation of allogeneic mesenchymal stem cell-based alveolar bone formation: preliminary findings. Clin Oral Implants Res 2003; 14: 481-9.

14.Öztopalan DF, Işık R, Durmuş AS. Yara iyileşmesinde büyüme faktörleri ve sitokinlerin rolü. Dicle Üniv Vet Fak Derg 2017; 10: 83-8.
15. Greenhalgh DG. Wound healing and diabetes mellitus. Clin Plastic Surg 2003; 30: 37-45.

16. Galiano RD, Michaels VJ, Dobryansky M, Levine JP, Gurtner GC. Quantitative and reproducible murine model of excisional wound healing. Wound Repair Regen 2004; 12: 485-92.

17. Blakytny R, Jude E. The molecular biology of chronic wounds and delayed healing in diabetes. Diabet Med 2006; 23: 594-608.

18. Larsen JA, Overstreet J. Pulsed radio frequency energy in the treatment of complex diabetic foot wounds: two cases. J Wound Ostomy Continence Nurs 2008; 35: 523-7.

19. Reid RR, Said HK, Mogford JE, Mustoe TA. The future of wound healing: Pursuing surgical models in transgenic and knockout mice. J Am Coll Surg 2004; 199: 578-85.

20.Guo SC, Tao SC, Yin WJ, Qi X, Yuan T, Zhang CQ. Exosomes derived from platelet-rich plasma promote the re-epithelization of chronic cutaneous wounds via activation of YAP in a diabetic rat model. Theranostics 2017; 7: 81-96.

21.Yuan T, Guo SC, Han P, Zhang CQ, Zeng BF. Applications of leukocyte- and platelet-rich plasma (L-PRP) in trauma surgery. Curr Pharm Biotechnol 2012; 13: 1173-84.

22. Wang F, Sun Y, He D, Wang L. Effect of Concentrated Growth Factors on the Repair of the Goat Temporomandibular Joint. J Oral Maxillofac Surg 2017; 75: 498-507.

23. Shih B, Garside E, McGrouther DA, Bayat A. Molecular dissection of abnormal wound healing processes resulting in keloid disease. Wound Repair Regen 2010; 18: 139-53.

24. Ulaşlı AM. Kas iskelet sistemi yaralanmalarında plateletten zengin plazma tedavisi. Kocatepe Tip Derg 2012: 13; 1-3.

25.Kim JM, Sohn DS, Bae MS, Moon JW, Lee JH, Park IS. Flapless transcrestal sinus augmentation using hydrodynamic piezoelectric internal sinus elevation with autologous concentrated growth factors alone. Implant Dent 2014; 23: 168-74.

26.Sohn D, Moon J, Moon Y, Park J, Jung H. The use of concentrated growth factors (CGF) for sinus augmentation. J Oral Implant 2009; 38: 25-38.

27. Khojasteh A, Eslaminejad MB, Nazarian H. Mesenchymal stem cells enhance bone regeneration in rat calvarial critical size defects more than platelete-rich plasma. Oral Surg Oral Med Oral Pathol Oral Radiol Endod 2008; 106: 356-63.

28. Falanga V, Iwamoto S, Chartier $\mathrm{M}$, et al. Autologous bone marrow-derived cultured mesenchymal stem cells delivered in a fibrin spray accelerate healing in murine and human cutaneous wounds. Tissue Eng 2007; 13: 1299-312.

29. Walter MN, Wright KT, Fuller HR, MacNeil S, Johnson WE. Mesenchymal stem cell-conditioned medium accelerates skin wound healing: an in vitro study of fibroblast and keratinocyte scratch assays. Exp Cell Res 2010; 316: 1271-81. 